\title{
Evaluation of Knowledge, Attitudes and Practices of Health Professionals in Front of the Exposure Accidents to Blood in Two Hospital Structures of Lubumbashi
}

\author{
Bakamona Lyna Babidi' ${ }^{1}$ Bianza Moise Bakadia1, Mulongo Pauline Kalenga1, \\ Kamona Charles Kimuni', Kabengele Arlette Ndaya ${ }^{1}$, Pembi Christian Kasongo1, \\ Tshibangu Victor Tshibanda', Kibi Ivonne Mwewa' ${ }^{2}$, H. E. Matala' , A. R. Kamb', \\ Mwema Gui Numbi'1, W. G. Sande1, Katolo Patrick Banza1, Koke Joelle Kibuluk1, \\ Kwete Mathieu Ngolo², Ilunga Eric Kasamba², Balaka Michel Ekwalanga²

\footnotetext{
${ }^{1}$ Higher Institute of Medical Techniques of Lubumbashi, Lubumbashi, R. D. Congo

${ }^{2}$ Faculty of Medicine, University of Lubumbashi, Lubumbashi, R. D. Congo

Email:linamuland@yahoo.fr, moisebakadia@gmail.com,Charleskimuni@gmail.com, victortshibanda@yahoo.fr, ruthkamb09@gmai.com,mwemaguy@yahoo.fr, Patrickbk600@gmail.com,drmathieungolo@gmail.com, ericaevanselies@gmail.com, miekwalanga@yahoo.fr
}

\begin{abstract}
How to cite this paper: Babidi, B.L., Bakadia, B.M., Kalenga, M.P., Kimuni, K.C., Ndaya, K.A., Kasongo, P.C., Tshibanda, T.V., Mwewa, K.I., Matala, H.E., Kamb, A.R., Numbi, M.G., Sande, W.G., Banza, K.P., Kibuluk, K.J., Ngolo, K.M., Kasamba, I.E. and Ekwalanga, B.M. (2017) Evaluation of Knowledge, Attitudes and Practices of Health Professionals in Front of the Exposure Accidents to Blood in Two Hospital Structures of Lubumbashi. Open Access Library Journal, 4: e3823.

https://doi.org/10.4236/oalib.1103823
\end{abstract}

Received: July 14, 2017

Accepted: August 7, 2017

Published: August 10, 2017

Copyright $\odot 2017$ by authors and Open Access Library Inc.

This work is licensed under the Creative Commons Attribution International License (CC BY 4.0).

http://creativecommons.org/licenses/by/4.0/

\begin{abstract}
The accidents of blood exposure are a real threat to the health personnel. According to our knowledge, in both hospitals, some actions in the prevention of accidents of blood exposure have been implemented. We have therefore conducted a survey about knowledge, attitudes and practices during the month of May 2013 in order to assess the current situation, to measure the overall level of knowledge and practices of personnel exposed. A survey was sent to 384 people using the interview technique directly. The salient results indicate that $81.3 \%$ of them admitted to having suffered from an accident of blood exposure and the results showed a good knowledge of the risk of contamination three HBV, HCV and HIV. The rate of vaccination against hepatitis B is $21.6 \% .61 .2 \%$ of accidents of blood exposure were occurred during recapping of needles, a gesture considered at risk. What to do in case of accidents of blood exposure appears to be insufficiently known by our sample. Accidents of blood exposure are still a concern in our community. Regular information and education office to best practice campaigns are needed to reduce the impact of these preventable incidents by simple measures.
\end{abstract}

\section{Subject Areas}

Pathology, Public Health 


\section{Keywords}

Accident Blood Exposure, Occupational Health Knowledge, Attitudes, Practice

\section{Introduction}

Any percutaneous contact (sting, cut) or mucous (eye, mouth) or injured skin (eczema, wound) with blood or a biological product containing blood for which the viral risk is proved is defined as an accident with exposure to blood. For other fluids, the risk of transmission of human immunodeficiency virus (HIV) and hepatitis $\mathrm{B}$ viruses (HBV) is considered to be possible for cerebrospinal, synovial, pleural, peritoneal, pericardial and amniotic. It seems therefore logical to consider risk exposures to these products, even if they are not visibly contaminated with blood such as blood exposure accidents [1]. The risk of occupational infections in the healthcare environment is potentially omnipresent. Biological fluids can carry the various infectious agents (bacteria, viruses, parasites and fungi). In practice, three viruses are to be feared: $\mathrm{HIV}, \mathrm{HBV}$ and hepatitis $\mathrm{C}$ virus (HCV) [2]. The risk is strongly related to the level of the patient's source plasma viral load at the time of the accident [3].

The place of accidents of blood exposure and biological fluids in the transmission of HIV/AIDS is not negligible. In industrialized countries, the majority of contamination and accidental seroconversions with $\mathrm{HBV}$ and HCV predominantly involve nurses (47\%) and laboratory workers (22\%) when injured by a sting. The cases of contamination by cutaneous-mucosal projection are much rare [2]. The major risk from exposure to blood and body fluids is shown in descending order by $\mathrm{HBV}$ in $30 \%, \mathrm{HCV}$ in $3 \%$, and $\mathrm{HIV}$ in $0.3 \%$ [1]. At the time of the generalization of standard precautions, the risk of viral transmission still appears as a distant statistic reserved for others, in the eyes of the majority of the healthcare staff. In the absence of vaccines-except for hepatitis B and radical solutions, the control strategy is based on staff awareness. This approach can only be successful if there is valid information on the knowledge, attitudes and practices of staff regarding the accident of exposure to blood. In the city of Lubumbashi, few actions have been carried out so far in the prevention of the accident of exposure to blood. We have therefore proposed to carry out a survey Kap (knowledge, attitudes and practices) which aims to evaluate the knowledge, attitudes and practices of staff working at the Jason Sendwe General Referral Hospital and the Saint Luke Polyclinic of Lubumbashi in front of the exposure accidents to blood.

\section{Materials and Methods}

This is a cross-sectional descriptive study carried out during the month of May 2013, with the staff of two hospital structures (Jason Sendwe General Hospital and Polyclinic Saint-Luc) in the city of Lubumbashi in the Democratic Republic 
of Congo. The target population was selected for all occupational categories at risk, working in both hospitals. General practitioners in public health were excluded from the study because they performed few practical acts exposing them to blood. Were Included all health professionals present on the days of the survey, after a free and informed consent. The information was collected by means of an anonymous survey with questions either closed or open. The variables studied were: socio-occupational characteristics, past experience of the accidents of blood exposure, knowledge of the accidents of blood exposure, measures to prevent or exposure to biological fluids and post-exposure management. In order to reduce the risk of disseminating survey content among those not yet interviewed, data collection was carried out over a very short period of time (6 hours for each healthcare professional). The survey was first tested on a few professionals to assess the understanding of the questions, the quality of the answers and estimate the time for each survey. The survey was distributed to all persons present on the days of the survey among the total number of 788 people, using the technique of face-to-face direct interview and allowing time for reflection for each reply. The number of health professionals responding was 384 (50\% of the total), including 302 at the Jason Sendwe Hospital and 82 at Polyclinic Saint-Luc. The agreement of the two doctors of the hospital before the investigation was carried out was obtained. Each record was identified by a number, thus ensuring the anonymity of the interviewee. The data was entered and evaluated using the Epi Info 2011 software (version 7.0.8.3). Analysis and interpretation used the calculation of proportion, mean and standard deviation.

\section{Results}

\subsection{Socioprofessional Characteristics of Respondents}

Table 1 presents the distribution of respondents by socio-professional characteristics. The male sex is predominant with $56.8 \%$ of the cases (sex ratio: 1.3 ). The mean age is $32 \pm 10$ years and the most common age range is 30 - 39 years, with $43.6 \%$ of respondents. The average length of service is $8 \pm 5$ years; $62.7 \%$ of the respondents had a seniority of between 1 and 10 years and $8.3 \%$ had a seniority of more than 20 years. The distribution of the respondents according to the service shows that the clinic leads the way with $16.4 \%$ of the cases followed by the gynecology-obstetrics and surgery departments each accounting for $16 \%$ of the cases. Nurses represent the most affected occupational group with $63.3 \%$.

\subsection{History of Blood Exposure Accidents}

Eighty-one point three percent $(312 / 384)$ of the respondents were victims of at least one the accidents of blood exposure during their professional practice, of which $77.6 \%$ were due to a needle bite. The projection of blood and/ or biological fluid contaminated with blood only concerns $9.3 \%$ of the accidents of blood exposure (29/312). Ninety point four percent (256/281) of the accidents of blood exposure that were due to a sting or cut were of a nature superficial. Sixty-one point two percent (191/312) of the accidents of blood exposure occurred during 
B. L. Babidi et al.

Table 1. Distribution of surveyed subjects according to socioprofessional characteristics.

\begin{tabular}{|c|c|c|}
\hline Variable & Effective $(n=384)$ & Percentage data \\
\hline \multicolumn{3}{|l|}{ Age } \\
\hline$<20$ years & 28 & 7,3 \\
\hline $20-29$ years & 107 & 27,8 \\
\hline $30-39$ years & 168 & 43,6 \\
\hline $40-49$ years & 74 & 19,2 \\
\hline$\geq 50$ years & 7 & 2,0 \\
\hline \multicolumn{3}{|l|}{ Sex } \\
\hline Famale & 166 & 43,2 \\
\hline Male & 218 & 56,7 \\
\hline \multicolumn{3}{|l|}{ Professional category } \\
\hline Nurse & 243 & 63,3 \\
\hline Doctor & 101 & 26,3 \\
\hline Laboratory technician & 23 & 6,0 \\
\hline Maids & 17 & 4,4 \\
\hline \multicolumn{3}{|l|}{ Service } \\
\hline Dispensary & 63 & 16,4 \\
\hline Surgery & 61 & 16,0 \\
\hline Obstetric gynecology & 61 & 16,0 \\
\hline Internal Medicine & 43 & 11,1 \\
\hline Pediatrics & 44 & 11,4 \\
\hline Neonatology & 31 & 8,0 \\
\hline Laboratory & 23 & 6,0 \\
\hline Other & 58 & 15,1 \\
\hline \multicolumn{3}{|l|}{ Seniority } \\
\hline$<1$ year & 44 & 11,4 \\
\hline $1-10$ years & 241 & 62,7 \\
\hline $11-20$ years & 67 & 17,5 \\
\hline$>20$ years & 32 & 8,3 \\
\hline
\end{tabular}

*other: emergency, dentistry, ophthalmology.

needle recapture, $21.1 \%(66 / 312)$ during work overload due to reduced staffing, and $2.3 \%$ (9/312) when the health professional was inexperienced. Thirty-one point one percent (122/312) of accidents of blood exposure occurred during injections, 20.5\% (64/312) during surgery, 5.4\% (17/312) during maintenance of premises and leaching. Antiretroviral prophylaxis was initiated to 37 agents (11.9\%) of accidents of blood exposure victims (Table 2).

\subsection{Knowledge about Blood-Borne Infectious Agents and Post-Exposure Attitudes}

All respondents were aware that they were at risk for blood-borne infections. For 
Table 2. Distribution of surveyed subjects by history of blood exposure accident.

\begin{tabular}{|c|c|c|}
\hline Variable & Effective & Percentage data \\
\hline \multicolumn{3}{|l|}{ Antecedent of exposure accidents to blood $(\mathrm{n}=384)$} \\
\hline Present & 312 & 81.3 \\
\hline Absent & 72 & 18.7 \\
\hline \multicolumn{3}{|l|}{ Nature of the exposure accidents to blood $(n=312)$} \\
\hline Needle sting & 242 & 77.6 \\
\hline Cutting a knife blade & 41 & 13.1 \\
\hline $\begin{array}{l}\text { Projection of blood or biological fluid contaminated } \\
\text { with blood }\end{array}$ & 29 & 9.3 \\
\hline \multicolumn{3}{|l|}{ Nature of the sting or cut $(n=283)$} \\
\hline Superficial & 256 & 90.4 \\
\hline Deep & 27 & 9.6 \\
\hline \multicolumn{3}{|l|}{ Post-exposure prophylaxis $(\mathrm{n}=312)$} \\
\hline Antiretroviral & 37 & 11.9 \\
\hline Nothing & 275 & 88.1 \\
\hline \multicolumn{3}{|l|}{$\begin{array}{l}\text { Circumstances of occurrence of exposure accidents to } \\
\text { blood }(\mathrm{n}=312)\end{array}$} \\
\hline When recapping needles & 191 & 61.3 \\
\hline More work / less staff & 66 & 21.1 \\
\hline Inexperienced health professional & 9 & 2.3 \\
\hline When disposing of medical waste & 17 & 5.4 \\
\hline In some very difficult care situations & 29 & 9.3 \\
\hline \multicolumn{3}{|l|}{$\begin{array}{l}\text { Task in progress at exposure accidents to blood } \\
\qquad(\mathrm{n}=312)\end{array}$} \\
\hline Injection & 122 & 39.1 \\
\hline Drip & 19 & 6 \\
\hline Transfusion & 34 & 10.9 \\
\hline Blood sample & 19 & 6 \\
\hline Delivery & 37 & 11.9 \\
\hline Surgery & 64 & 20.5 \\
\hline Maintenance of premises and leaching & 17 & 5.4 \\
\hline
\end{tabular}

the infectious agent transmitted by blood, all respondents were aware that HIV was transmissible; The transmission of HBV and HCV by blood was known respectively in $82(316 / 384)$ and $89.9 \%$ (345/384) of the respondents. Of the 384 respondents, $89.4 \%$ (343/384) felt that reporting should be done in the case of exposure accidents to blood, and in $45 \%$ (155/343) cases the referring physician was the most cited referent followed by staff Administrative officer (36\%) and 
the head of department (19\%). According to $30 \%$ of respondents, the declaration must be made within 48 hours to the administration as an industrial accident. However, $88.1 \%$ (275/312) of those who had had an accident of blood exposure had not reported their accidents (Table 3). The main reasons cited are shown in Figure 1 and are dominated by ignorance of the reporting procedure in $66.1 \%$ of cases $(186 / 275)$.

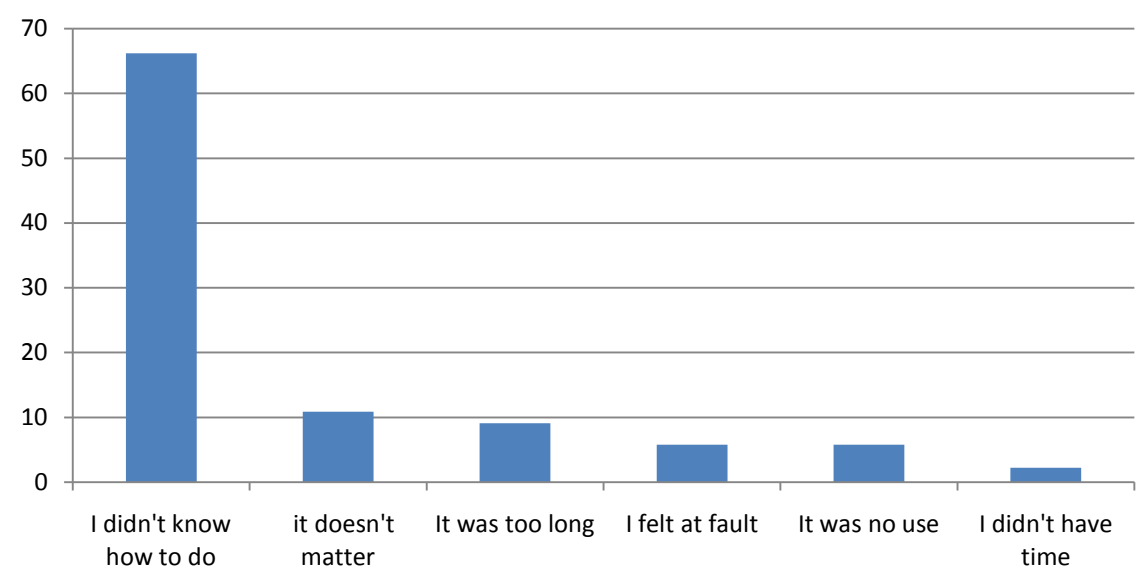

Figure 1. Reason of no declaration.

Table 3. Distribution of subjects surveyed according to knowledge about blood-borne infectious agents and post-exposure attitudes.

\begin{tabular}{|c|c|c|}
\hline Variable & Effective & Percentage data \\
\hline \multicolumn{3}{|c|}{$\begin{array}{l}\text { Knowledge of risk of transmitted bloodborne infec- } \\
\text { tions }(n=384)\end{array}$} \\
\hline Yes & 384 & 100 \\
\hline No & 0 & 0 \\
\hline \multicolumn{3}{|c|}{$\begin{array}{l}\text { Knowledge of bloodborne infectious agents } \\
\qquad(n=384)\end{array}$} \\
\hline \multicolumn{3}{|l|}{ HIV } \\
\hline Yes & 384 & 100 \\
\hline No & 0 & 0 \\
\hline \multicolumn{3}{|l|}{ HBV } \\
\hline Yes & 316 & 82 \\
\hline No & 68 & 18 \\
\hline \multicolumn{3}{|l|}{$\mathrm{HCV}$} \\
\hline Yes & 345 & 89.9 \\
\hline No & 39 & 10.1 \\
\hline \multicolumn{3}{|c|}{ Declaration of exposure accidents to blood $(\mathrm{n}=312)$} \\
\hline Yes & 275 & 88.1 \\
\hline No & 37 & 11.9 \\
\hline
\end{tabular}




\subsection{The Management}

Most respondents (85.6\%); victims of accidents of blood exposure had disinfected the wound during the accident, $8.6 \%$ had wound dressings compared to $5.8 \%$ who had done an abundant wash with soap and water. According to the respondents, disinfection was based on several products: $63 \%$ of accidents of blood exposure victims disinfecting the wound during the accident used denatured alcohol, 19.9\% used Bétadine against 1.9\% who used bleach. Ninety-seven point eight percent (97.8\%) of the source patients were HIV-negative versus 2.2\% HIV-positive. Ninety-seven point eight percent (97.8\%) of the source patients were unaware of their serology for HBV, $1.3 \%$ were HBV-negative versus $0.9 \%$ who were positive HBV discovered. Ninety-eight point eight percent (97.8\%) of the source patients were unaware of their serologic status for HCV, $1.3 \%$ were HCV-negative compared to $0.9 \%$ who were positive HCV detected. One hundred percent (100\%) of accidents of blood exposure victims had at least one initial serological test. A prophylactic ARV treatment was established in 37 agents, $11.9 \%$ of the victims against 275 agents or $88.1 \%$ who had not had anARV prophylactic treatment. Eighty-six percent (81\%) of ARV victims had discontinued treatment, compared to $19 \%$ who had not stopped treatment. Eightysix point seven (86.7\%) of ARV-treated patients had discontinued prophylactic treatment because of unbearable side effects, compared with $13.3 \%$ who discontinued it because of the HIV-negative serologic status of the source patient (Table 4).

\subsection{Prevention of the Accidents of Blood Exposure}

Seventy-eight point four percent (301/384) of our respondents used gloves satisfactorily when administering care, compared with $21.6 \%$ (83/384) who did not have a satisfactory use of gloves. One hundred percent (384/384) of our respondents used soaps when washing hands. One hundred percent of our respondents used decontamination procedures for care equipment. Thirty-two decimal five percent (125/384) of our respondents had procedures for decontaminating health care equipment posted in their service against 67.5\% (259/384) who had not posted. Ninety-six percent (96\%) of our respondents used the incinerator for the treatment of biomedical waste, compared to $4 \%$ of those who land filled. Recycling and composting were not practiced by our respondents. The hygiene of the premises and daily cleaning are $100 \%$ good at the Saint-Luc polyclinic against $0.7 \%$ at the HGR Sendwe. Eighty-two decimal five percent (82.5\%) of our respondents were wearing protective equipment against bloodshed, compared with $17.5 \%$ who did not. Among the respondents, $78.4 \%$ were unvaccinated against hepatitis B compared with $21.6 \%$ who were vaccinated. The efficacy of vaccination with an anti-HBS antibody assay was not tested in any of the respondents Table 5 .

\subsection{Level of Awareness of Accidents of Blood Exposure}

Almost all respondents (92\%) reported that they had never received training in 
accidents of blood exposure and did not know how to prevent them. Everyone wants to know more about this subject.

Table 4. Management of victims of accidents of blood exposure.

\begin{tabular}{|c|c|c|}
\hline Variable & Effective & Percentage data \\
\hline \multicolumn{3}{|c|}{$\begin{array}{l}\text { Immediate care in case of accidents of blood exposure } \\
\qquad(\mathrm{n}=312)\end{array}$} \\
\hline Wound disinfection & 267 & 85.6 \\
\hline Abundant washing with soap and water & 18 & 5.8 \\
\hline Pansement de la plaie & 27 & 8.6 \\
\hline \multicolumn{3}{|l|}{ Products used for wound disinfection $(n=267)$} \\
\hline Betadine & 53 & 19.9 \\
\hline Denatured alcohol & 168 & 63 \\
\hline Bleach & 5 & 1.9 \\
\hline Soap & 41 & 13.3 \\
\hline \multicolumn{3}{|l|}{ HIV source serology for HIV $(n=312)$} \\
\hline Positive discovery & 7 & 2.2 \\
\hline Negative & 305 & 97.8 \\
\hline \multicolumn{3}{|l|}{ Serology of source patients for HBV $(n=312)$} \\
\hline Positive discovery & 3 & 0.9 \\
\hline Negative & 4 & 1.3 \\
\hline Unknown & 304 & 97.8 \\
\hline \multicolumn{3}{|l|}{ Serology of source patients for HCV $(n=312)$} \\
\hline Positive discovery & 7 & 2.2 \\
\hline Negative & 305 & 97.8 \\
\hline \multicolumn{3}{|c|}{ Prophylactic treatment of NSA victims $(n=312)$} \\
\hline Arvs & 37 & 11.9 \\
\hline Nothing & 275 & 88.1 \\
\hline \multicolumn{3}{|l|}{ Interruption of ARV treatment $(n=37)$} \\
\hline Yes & 30 & 81 \\
\hline No & 7 & 19 \\
\hline \multicolumn{3}{|l|}{ Reasons for discontinuing treatment $(n=30)$} \\
\hline HIV negative patient source & 4 & 13.3 \\
\hline Unbearable side effects & 26 & 86.7 \\
\hline
\end{tabular}


Table 5. Prevention of the accidents of blood exposure.

\begin{tabular}{|c|c|c|}
\hline Variable & Effective & Percentage data \\
\hline \multicolumn{3}{|c|}{ Satisfactory use of gloves $(n=384)$} \\
\hline Yes & 301 & 78.4 \\
\hline No & 83 & 21.6 \\
\hline \multicolumn{3}{|c|}{ Use of soap during washing $(n=384)$} \\
\hline Yes & 384 & 100 \\
\hline No & 0 & 0 \\
\hline \multicolumn{3}{|c|}{$\begin{array}{l}\text { Existence of decontamination procedures for nursing } \\
\text { equipment }(\mathrm{n}=384)\end{array}$} \\
\hline Yes & 384 & 100 \\
\hline No & 0 & 0 \\
\hline \multicolumn{3}{|c|}{$\begin{array}{l}\text { Displays of procedures for the decontamination of } \\
\text { health care equipment }(n=384)\end{array}$} \\
\hline Yes & 125 & 32.5 \\
\hline No & 259 & 67.4 \\
\hline \multicolumn{3}{|c|}{ Treatment of biomedical waste $(\mathrm{n}=384)$} \\
\hline Incineration & 368 & 96 \\
\hline Burying & 16 & 4 \\
\hline \multicolumn{3}{|c|}{$\begin{array}{l}\text { Room hygiene and daily cleaning for HGR Sendwe } \\
\qquad(\mathrm{n}=302)\end{array}$} \\
\hline Respected (good) & 2 & 0.7 \\
\hline Not respected (bad) & 67 & 22.1 \\
\hline \pm respected (average) & 233 & 77.2 \\
\hline \multicolumn{3}{|c|}{$\begin{array}{l}\text { Hygiene of premises and daily cleaning for polyclinic } \\
\text { saint Luc }(n=82)\end{array}$} \\
\hline Respected (good) & 82 & 100 \\
\hline Not respected (bad) & 0 & 0 \\
\hline \pm respected (average) & 0 & 0 \\
\hline \multicolumn{3}{|c|}{$\begin{array}{l}\text { Use of blood-sprayed and/or blood-borne splash } \\
\text { materials }(n=384)\end{array}$} \\
\hline Yes & 317 & 82.5 \\
\hline No & 67 & 17.5 \\
\hline \multicolumn{3}{|c|}{ Hepatitis B Vaccine Status $(n=384)$} \\
\hline Vaccinated & 83 & 21.6 \\
\hline Not vaccinated & 301 & 78.4 \\
\hline
\end{tabular}

\section{Discussion}

\subsection{Socioprofessional Characteristics of Respondents}

Of the 384 respondents, 218 or $56.8 \%$ were male compared to 166 or $43.2 \%$ of 
the female. These findings are similar to those of Rabaud among health care workers, where $60 \%$ were male and $40 \%$ female [4]. The preponderance of male agents observed in our study reflects the usual inequality and discrimination in the employment of women in our society. The biggest male representation in both health facilities explains this phenomenon.

The mean age is $32 \pm 10$ years and the most common age range is 30 - 39 years with $43.6 \%$ of respondents joining the Koné study In Mali who had found an average age of $35.4 \pm 9$ years [5]. Average professional tenure is $8 \pm 5$ years. However, in the study by Laraqui; The average age was $40.8 \pm 7.8$ years and the average length of service was $15.6 \pm 7.4$ years [6].Nurses represent the occupational category most concerned with $63.3 \%$ joining the study made by Loft or $69 \%$ of the respondents were nurses [3]. These results also join the study of Asseray and Eholie where respectively 63 and 57, 4\% of respondents were nurses [7] [8]. In the study by Sako, The majority of respondents were physicians (38.6\%) and internal physicians (34.4\%) with 56 years of professional experience of 5 years or less in $56.3 \%$ of cases [9].

\subsection{History of the Accidents of Blood Exposure}

In our study, more than $80 \%$ of respondents were already victim of less than one The accidents of blood exposure, joining a study carried out in Casablanca in 1988 which had found a rate of $81 \%$ of the victims of the accidents of blood exposure; While a cross-sectional survey in Abidjan in 1999 and 2002 showed this history of the accidents of blood exposure in 60\% of cases [8] [10]. These results also coincide with the study by Laraqui in Morocco and Sako in Guinea Conackry who had found $58.9 \%$ and $55.8 \%$ of accidents of blood exposure victims respectively [6] [9]. In the Asseray study, $47.2 \%$ of respondents to a specific question reported having had at least one blood accident. The rate was highest for nurses (58\%), but present in all occupational categories joining our study [7]. The study by Ennigrou In a surgery unit in Tunis in 2002 revealed that $32 \%$ of the staff interviewed had at least one accidents of blood exposure in the last 12 months, joining a study carried out in 1997 in 5 of the largest hospitals in Tunisia that had estimated the incidence (4\%), which also corresponds to that recorded in the public care structures of Paris hospitals in 1994, which was $4.25 \%$ [11].

Concerning the circumstances of the occurrence of the accidents of blood exposure, needle recapture was the most frequent, accounting for $61.2 \%$ of accidents of blood exposure victims, which is close to the study by Bouvet For whom recapping is a very usual gesture in $2 / 3$ of the caregivers [12]. Specific training reduces the recapping frequency by $17 \%$ according to Bouvet and by $24 \%$ according to Lert [10]. Rabaud's study reports that this are inexperienced people who least respect the precautions such as not recapping needles and wearing gloves [4]. In our study, apart from needle recapture, we found that there were other circumstances in which the accidents of blood exposure occurred, such as 
overwork and an inadequate number of health workers, which accounted for 21.1\% Public assistance of Paris hospitals for 1050 cases of accidents of blood exposure, among the factors favoring the occurrence of accidents of blood exposure were: a context of overwork $48.7 \%$, an inadequate staff of staff $24 \%$ [13]. In our study, most of accidents of blood exposure (39.1\%) occurred during injections joining the work of Eholie and Koné, who found $44 \%$ and $73.2 \%$ respectively [5] [8].

\subsection{Knowledge about Bloodborne Infectious Agents and Post-Exposure Attitudes}

As regards knowledge of the blood transmission of these three viruses, our study showed a good knowledge of HIV transmission is $100 \%$ of respondents, $82 \%$ of HCV and 89.9\% of HBV joining the study Binard and Ennigrou [10] [14]. In the Koné study in Mali, the main communicable infectious agents (HIV, HBV and HCV) were ignored by $76.6 \%$ [5]. These three viruses constitute the bulk of the risk of transmission to caregivers in case of accidents of blood exposure because of their prevalence and the severity of the consequences [14]. The risk associated with accidents of blood exposure represents a real threat to health professionals, our study found that $100 \%$ of respondents were aware of the reality of the care-treated transmission mand therefore the reality of risk. The risk of viral transmission is $0.3 \%$ for HIV, $3 \%$ for HCV and $30 \%$ for HBV [2]. With regard to knowledge about accidents of blood exposure, our study showed that more than $90 \%$ of the health professionals surveyed were aware of the accidents of blood exposure joining the ENNIROU et al study, in which more than $85 \%$ The existence of accidents of exposure to blood [10]. In connection with the accidents of blood exposure declaration, our study highlights an under-reporting of accidents of blood exposure. Indeed, $88.1 \%$ of the victims of the accidents of blood exposure have never declared it; Joining the study of Hamory which found in a study or survey of 1.499 caregivers that $40 \%$ of the accidents of blood exposure occurred during the year of study were not reported. The accidents of blood exposure in previous yearms did not give rise to a declaration [4].

In the work of Lymer, $91 \%$ of the accidents of blood exposure were not reported, whereas this rate was $35 \%$ in the Nalsing study, despite the fact that it was an infectious disease service taking Patients with HIV [15]. In the study by Laraqui, $58.9 \%$ of people had been the victim of at least one blood-related accident, of which 5.8\% were reported [6]. However, in the work of Eholie, about 60 percent of victims of blood exposure accidents, $15 \%$ reported their accident but $84.6 \%$ acknowledged the need to report any accidents of blood exposure [8]. In the work of Asseray, the systematic declaration of any accident of exposure to blood was recognized by $97 \%$ of the respondents; (81\%) or the supervisor of the service $(75 \%)$. Of all respondents, $34 \%$ reported within the first hour of the blood exposure accident, citing HIV prophylaxis, and 41\% reported within 24 hours [7]. Under-reporting is an obstacle to a constant epidemiological assessment of the impact of accidents of blood exposure. It prevents systematic man- 
agement of accidents of blood exposure, causes the victim to lose the seroconversion and benefits from the recognition of the accident at work and causes a probable loss of chance by delaying the treatment of a possible infection with HIV, HCV or HBV [10]. In the studies by Denis in France and Jeff In the USA, the hypothetical certainty about non-infection of the patient appeared to be a strong reason for non-reporting [10]. Up-to-date hepatitis B vaccination, Most often without control of vaccine efficiency, falsely reassures some staff members who obscure the risk of HIV infection and HCV [4]. In the study by Koné, Consulting a Doctor Referral after an the accidents of blood exposure was compulsory according to $32 \%$. The 48 -hour deadline for reporting the accidents of blood exposure was known by $51.3 \%$ [5]. There is a confusion between the statutory deadline for reporting to the administration as an accident (48 hours) for public sector employees and the need to contact the referring physician promptly for early care [10].

\subsection{Prevention of Accidents of Blood Exposure}

Despite high levels of BSE, vaccination against hepatitis B remains insufficient in the Democratic Republic of Congo. Our results show that only $21.6 \%$ of respondents reported having been vaccinated against hepatitis $B$. While the study by Ennigrou shows that $2 / 3$ of those surveyed were vaccinated, as was a national study French among 5000 health workers shows that $79.2 \%$ of them were also [10] [16]. In the studies of Laraqui, only $40.6 \%$ of the staff were adequately vaccinated against hepatitis B (97\% of those vaccinated would develop protective antibody levels (10UI/ L) Post-vaccine serology performed in $1.8 \%$ of the vaccinates) [6]. In the study by Sako et al., 50\% were not vaccinated against hepatitis $\mathrm{B}$ and $30.2 \%$ did not know their HIV status at the time of the survey [9]. Our study showed that the wearing of gloves is a measure respected according to the statements of the respondents in $94.2 \%$ of the cases against $17 \%$ in the works of Rabaud [4]. In the study of Koné et al., the interview revealed that $78.9 \%$ of the patients were wearing gloves during the treatment [5]. However, in the study by Sako, the non-wearing of gloves was $62.5 \%$ [9]. Wearing gloves has an important place in the prevention of the accidents of blood exposure, preventing skin contact with blood and/or body fluids and reducing the inoculum during a sting [17].

In our survey, abundant washing with soap and water was cited only by $5.8 \%$ of respondents, the priority use of disinfectant is $85.6 \%$ corresponding to the recommendations in force, the dressing is reported by $8.6 \%$ of respondents against $21.2 \%$ in the ennigrou study [10]. In the Koné study, the notion of washing and disinfection after an accident of blood exposure was known by 68.8\%. Applied disinfectant was correct for $21.9 \%$ and application time for $69.5 \%$ [5]. In relation to the treatment of biomedical waste, $96 \%$ of respondents incinerated waste as opposed to $4 \%$ who landed. Recycling and composting were not cited by our respondents. Indeed, the mismanagement of this waste, in particular its manipulation by a third person who does not know their contents, 
may be at the origin of the accidents of blood exposure with serious consequences. One hundred percent (100\%) of our respondents used decontamination procedures for care equipment. Thirty-two decimal five percent $(32.5 \%)$ of our respondents had procedures for decontaminating health care equipment posted in their department compared to $67.5 \%$ who had not posted. Perdesen, in a hospital survey covering a period of 4 years, showed the link between workplace contamination and non-compliance with procedures for the decontamination of health care equipment in $86 \%$ of cases [15].

\subsection{Supported}

Regarding the care of the accidents of blood exposure, it should be noted that 37 victims, or $12 \%$ were treated with $\mathrm{ARV}$, compared with $88 \%$ who were not in care. However, in the study by Eholie et al., in our study, 30 victims or $81 \%$ had stopped their prophylactic treatment against $19 \%$ who had completed their ARV cure; $86.7 \%$ of the victims had interrupted it because of unbearable side effects compared with $13.3 \%$ who had done so because of the negative HIV serology of the source patient. Thus, the recommendations of management appear to be poorly followed in our context. This is all the more worrying since it proves insufficient since in France as an illustration, victims are advised to protect their sexual intercourse during the month following accidental exposure in order to avoid confounding factors. It is also advisable to avoid blood donation by exposure accidents to blood victims during the next 6 months of the accident [4].

\subsection{Degree of Awareness of Accidents of Blood Exposure}

In our study, almost all respondents (92\%) said they had never received training in ESA and did not know how to prevent them. Everyone wants to know more about this subject.

Even without formally demonstrating this, this study suggests disparities in knowledge and practice of the accidents of blood exposure between different occupational categories. The need for targeted training and education between categories of health professionals was also mentioned by Chevalier and his team in a study carried out in Senegal [18].

\section{Conclusions}

The risk of transmission of diseases due to accidents of exposure to blood although very low is very real. Moreover, cases of transmission of HIV, HBV and HCV have been reported in the literature.

Apart from hepatitis B vaccination, the prevalence of accidents of blood exposure and the awareness of risk by healthcare professionals remain the best protection. The reduction in the incidence of the accidents of blood exposure requires the respect of standard precautions and the proper use of safety equipment. The prevention of the accidents of blood exposure is part of the improvement of the working conditions of health personnel and epidemiological sur- 
veillance is the key to this, since it is an indispensable complement to the prevention efforts undertaken and makes it possible to identify circumstances of occurrence of the accidents of blood exposure and to determine the actions to be taken (Information-Training, organization of work, preparation of protocol of care including staff security and choice of equipment). The results of this work must nevertheless be interpreted in the limits of this work, its transversal nature and restricted to the two health facilities that allow an extrapolation to the whole city. This study has the advantage of having reported the actual level of the accidents of blood exposure risk knowledge of health professionals from our above-mentioned study setting. It reinforces the professional interest of education in all occupational categories through real change in behavior.

\section{Abbreviations Used}

HIV: Human Immunodeficiency Virus;

HBV: Hepatitis B virus;

HCV: Hepatitis C virus;

AIDS: Acquired Immunodeficiency Syndrome.

\section{Authors' Contribution}

All authors contributed in the different phases of the research.

\section{References}

[1] Blood Exposure Study Group (2012) Task Force on Blood Exposure. National Surveillance of Blood Exposure Accidents-RAISIN 2012.

[2] World Health Organization (1999) Guide for the Prevention of HIV and Hepatitis among Health Professionals. World Health Organization, Paris, 93.

[3] Institute of Medical and Veterinary Science (2008) Monitoring of Occupational Contamination with HIV, HCV and HBV in Health Personnel. Situation as at 31 December 2007. Institute of Medical and Veterinary Science, Adelaide, 1-6.

[4] Rabaud, C. (2003) Analysis of the Behavior of Healthcare Workers in Relation to Blood Exposure Accidents. Hygiene, 11, 169-175.

[5] Binard, F. and Capdenatraymond, E. (2006) The Knowledge, Skills and Practices Questionnaire as a Tool for Assessing Professional Practices: About a Survey of Blood Exposure Accidents in a Health Facility. Hygiene, 14, 326-334.

[6] Ennigrou, S., Benameurkuleine, I., Chérif, A., Najah, N. and Benhamida, A. (2003) Analysis of the Knowledge, Attitudes and Practices of Healthcare Workers in Relation to Blood Exposure Accidents in General Surgery. La Tunisie Medicale, 82, 492 505.

[7] Hamza, R. (2003) Hospital Infection. 1st Edition, MSP-DHMPE, Tunis, 152-164.

[8] Jahanet, H., Tarantola, A. and Bouvet, E.G. (2000) Means of Protection in the Operating Room and Blood Exposure Accidents. Hygiene, 8, 107-112.

[9] Gehanno, J.F. (2003) Immunization of Health Professionals against Hepatitis B. Hygiene, 11, 156-166.

[10] Caillard, J.F., Iwatsubo, Y., Gehanno, J.F. and Saurel, D. (2003) Eleven Years of Blood Exposure Accidents Supervision at Public Assistance-Paris Hospitals. Hy- 
giene, 11, 108-111.

[11] Abiteboul, D., Fargeot, C., Deblangy, C. and Lucet, J.C. (2003) The Glove and Accidents of Exposure to Blood. Hygiene, 11, 121-124.

[12] Perdesen, E.B. (1996) Potentially Hasardous Exposure to Blood among Hospital Personnel. A Retrospective Study of Systemically Registeed Exposure during the Period 1990-1994. Ugeskrlaeger, 158, 1807-1811.

[13] Chevalier, B., Margery, J., Wade, B., Ka, S., Diatta, B., Gueye, M., et al. (2008) Perception of Nosocomial Risk among Hospital Staff at the Principal Hospital of Dakar. Medecine Tropicale, 68, 593-596.

[14] Asseray, N., Alfandari, S., Vandenbussche, C., Guery, B., Parent, K., Georges, H., et al. (1998) Analysis of Practices and Knowledge about Blood Exposure Accidents. Medicine and Infectious Diseases, 28, 612-617.

[15] Laraqui, O., Laraqui, S., Tripodi, D., Zahraoui, M., Caubet, C., Orchard, C., et al. (2008) Assessment of Knowledge, Attitudes and Practices on Blood Exposure Accidents in Healthcare Settings in Morocco. Medicine and Infectious Diseases, 38, 658666.

[16] Sako, F., Tounkara, M., Traore, F., Soumah, M., Kuitchet, N. and Cissé, M. (2013) Knowledge and Practice of Nursing Staff on Blood Exposure Accidents at the Donka National Hospital (Conakry). Medical Guinea, No. 79.

[17] Eholie, S., Ehui, E., Yebouet, K., Simo, T., Tanon, T., Coulibaly, D., et al. (2002) Analysis of Practices and Knowledge of Health Care Workers on Blood Exposure Accidents in Abidjan (Ivory Coast). Medicine and Infectious Diseases, 32, 359-368.

[18] Koné, M. and Mallé, K. (2015) Accidents of Exposure to Blood: Knowledge and Practices of the Health Personnel of a Hospital in Mali. Bulletin of the Society of Exotic Pathology, 108, 369-372. https://doi.org/10.1007/s13149-015-0451-4

Submit or recommend next manuscript to OALib Journal and we will provide best service for you:

- Publication frequency: Monthly

- 9 subject areas of science, technology and medicine

- Fair and rigorous peer-review system

- Fast publication process

- Article promotion in various social networking sites (LinkedIn, Facebook, Twitter, etc.)

- Maximum dissemination of your research work

Submit Your Paper Online: Click Here to Submit

Or Contact service@oalib.com 